\title{
Curcumin alone and in combination with augmentin protects against pulmonary inflammation and acute lung injury generated during Klebsiella pneumoniae B5055-induced lung infection in BALB/c mice
}

\author{
Shruti Bansal and Sanjay Chhibber
}

Correspondence

Sanjay Chhibber

sanjaychhibber8@gmail.com

Received 19 October 2009

Accepted 23 December 2009

\author{
Department of Microbiology, Panjab University, Chandigarh 160014, India
}

\begin{abstract}
Acute lung injuries due to acute lung infections remain a major cause of mortality. Thus a combination of an antibiotic and a compound with immunomodulatory and anti-inflammatory activities can help to overcome acute lung infection-induced injuries. Curcumin derived from the rhizome of turmeric has been used for decades and it exhibits anti-inflammatory, anti-carcinogenic, immunomodulatory properties by downregulation of various inflammatory mediators. Keeping these properties in mind, we investigated the anti-inflammatory properties of curcumin in a mouse model of acute inflammation by introducing Klebsiella pneumoniae B5055 into BALB/c mice via the intranasal route. Intranasal instillation of bacteria in this mouse model of acute pneumonia-induced inflammation resulted in a significant increase in neutrophil infiltration in the lungs along with increased production of various inflammatory mediators [i.e. malondialdehyde (MDA), myeloperoxidase (MPO), nitric oxide (NO), tumour necrosis factor (TNF)- $\alpha$ ] in the lung tissue. The animals that received curcumin alone orally or in combination with augmentin, 15 days prior to bacterial instillation into the lungs via the intranasal route, showed a significant $(P$ $<0.05)$ decrease in neutrophil influx into the lungs and a significant $(P<0.05)$ decrease in the production of MDA, NO, MPO activity and TNF- $\alpha$ levels. Augmentin treatment alone did not decrease the MDA, MPO, NO and TNF- $\alpha$ levels significantly $(P>0.05)$ as compared to the control group. We therefore conclude that curcumin ameliorates lung inflammation induced by $K$. pneumoniae B5055 without significantly $(P<0.05)$ decreasing the bacterial load in the lung tissue whereas augmentin takes care of bacterial proliferation. Hence, curcumin can be used as an adjunct therapy along with antibiotics as an anti-inflammatory or an immunomodulatory agent in the case of acute lung infection.
\end{abstract}

\section{INTRODUCTION}

Klebsiella pneumoniae is an opportunistic pathogen that causes community-acquired and nosocomial infections, mainly in immunocompromised individuals. Infections caused by it range from mild urinary infections to severe bacteraemia and pneumonia with a high rate of mortality and morbidity (Cortes et al., 2002; Struve \& Krogfelt, 2004). Various antibiotics have been used to treat infections caused by $K$. pneumoniae but emergence of strains resistant to commercially available antibiotics has made the treatment of infections quite difficult (Saint \& Chenoweth, 2003). The combination of amoxicillin and clavulanic acid, i.e. augmentin, has been the first choice of treatment for communityacquired as well as nosocomial lower respiratory tract infections (Legnani, 1997). This is because of the presence of the clavulanate component, which protects the amoxicillin component from degradation by $\beta$-lactamases produced by

Abbreviations: MDA, malondialdehyde; MPO, myeloperoxidase; NO, nitric oxide; TNF, tumour necrosis factor. this organism, thereby retaining its original potency and antibacterial activity against Klebsiella (Hunter et al., 1980).

Most antibiotics reduce bacterial load and do not provide protection against organ damage generated because of an exaggerated immune response (Woo et al., 2002). In order to control the over-stimulated stage of inflammation, various strategies have been used in the past, such as the use of various corticosteroids for the treatment of Mycobacterium tuberculosis infection, use of anti-tumour necrosis factor (TNF) antibodies or TNF blockers, cyclooxygenase (COX-2) inhibitors, and leukotriene synthetase and 3-hydroxy-3-methylglutaryl coenzyme A reductase inhibitors (Tasaka et al., 2002). However, most of these agents failed during clinical trials and did not provide protection to patients suffering from acute infections (Tasaka et al., 2002). Therefore, there is a need for newer immunomodulatory agents to be developed which target only the overwhelming activity of the immune system while keeping its protective function intact. The combination of an anti-inflammatory agent with an antibiotic can serve as a good option in 
containing both the infectious agent as well as the harmful action of the over-stimulated immune response. One such herbal compound is turmeric-derived curcumin, which is known to possess anti-inflammatory properties and has been used for decades to curb inflammation (Huang et al., 1994, 1997; Kawamori et al., 1999; Sharma et al., 2005).

Curcumin is a naturally occurring yellow pigment found in the spice turmeric derived from the rhizome of the plant Curcuma longa. It has been used for centuries in the Indian subcontinent as a dietary spice and for the treatment of a variety of illnesses, such as the common cold, coughs, jaundice, inflammatory bowel conditions, arthritis, etc. (Ammon \& Wahl, 1991). Extensive research has shown that curcumin mediates its antiinflammatory effects through the downregulation of inflammatory transcription factors (such as nuclear factor $\kappa \mathrm{B}$ ), enzymes (such as COX-2 and 5-lipoxygenase) and cytokines (such as TNF, interleukin-1 and interleukin-6) (Aggarwal \& Sung, 2008). Curcumin has been characterized as safe by health authorities such as the Food and Drug Administration in the USA, and the Food and Agriculture Organization/World Health Organization. Curcumin has entered the phase I and II clinical trial level in the last 10-15 years (Strimpakos \& Sharma, 2008) and phase I studies show that people can tolerate curcumin at a dose as high as $8 \mathrm{~g}$ per day (Cheng et al., 2001).

Working in this direction, we tried to evaluate the pulmonary inflammatory damage in compartmentalized inflammation in a mouse model of pneumonia and evaluated the protective potential of a herbal compound, curcumin, alone and along with augmentin.

\section{METHODS}

Bacterial strain. Klebsiella pneumoniae B5055 (O1:K2), initially obtained from Dr Mathia Trautmann, Department of Medical Microbiology and Hygiene, University of Ulm, Germany, and maintained in the laboratory, was used in the study. This strain was selected because it expresses $\mathrm{O} 1$ and $\mathrm{K} 2$ serotypes, which are the most commonly encountered $\mathrm{O}$ and $\mathrm{K}$ types found in a clinical situation.

Animals. A total of 80 pathogen-free BALB/c mice of either sex, 6-8 weeks old, weighing 20-25 g were procured from the central animal house of Panjab University, Chandigarh, India. Animals were kept in clear polypropylene cages and fed on a standard antibiotic-free diet (Hindustan Lever Products, Kolkata, India) and water ad libitum. The temperature ranged between 18 and $22{ }^{\circ} \mathrm{C}$ and the relative humidity was between 55 and $65 \%$. The study was conducted after obtaining approval from the animal ethical committee of Panjab University.

Curcumin used in the study was obtained from Sigma Aldrich.

Experimental protocol. Mice were randomly divided into four groups and each group comprised 20 animals. Different groups were given one of the following treatments: (a) mice infected with K. pneumoniae B5055 were given no standard drug treatment and received only normal saline orally; (b) mice received an intraperitoneal injection of an antibiotic, augmentin (a combination of amoxicillin and clavulanic acid), at a dose of $20 \mu \mathrm{g} \mathrm{ml}^{-1}, 24 \mathrm{~h}$ after establishment of infection with K. pneumoniae B5055; (c) mice were fed on curcumin $\left(150 \mathrm{mg} \mathrm{kg}^{-1}\right)$ for 15 days and thereafter infected intranasally with $K$. pneumoniae B5055; (d) mice were fed on curcumin $\left(150 \mathrm{mg} \mathrm{kg}^{-1}\right)$ for 15 days, infected with $\mathrm{K}$. pneumoniae
B5055 and received an intraperitoneal injection of augmentin, at a dose of $20 \mu \mathrm{g} \mathrm{ml}^{-1}, 24 \mathrm{~h}$ after the establishment of infection.

Induction of acute lung infection. Acute lung infection in mice was induced with $K$. pneumoniae B5055, following the original method of Held et al. (1998) modified by Yadav et al. (2003). A single isolated colony of $K$. pneumoniae $\mathrm{B} 5055$ obtained on a nutrient agar plate was transferred to $50 \mathrm{ml}$ nutrient broth and incubated at $37{ }^{\circ} \mathrm{C}$ for $18 \mathrm{~h}$. Cells were harvested by centrifugation at 5000 r.p.m. for $15 \mathrm{~min}$. The bacterial pellet so obtained was given three washings with sterile PBS (0.1 M, pH 7.2). The final pellet was suspended in a minimum volume of PBS $(0.1 \mathrm{M}$, $\mathrm{pH}$ 7.2) to get the desired concentration $\left(\mathrm{OD}_{600}=0.03,10^{4}\right.$ c.f.u. $\left.\mathrm{ml}^{-1}\right)$.

Mice were then given $10^{4}$ c.f.u. $\mathrm{ml}^{-1}$ of $K$. pneumoniae B5055 intranasally in a volume of $50 \mu \mathrm{l}$ while holding the mouse in an upright position without any anaesthesia. After infection, animals were sacrificed on different days post-infection by cervical dislocation and lungs were removed aseptically and examined for bacterial load and various other inflammatory parameters.

Quantification of bacteria in lungs. Mice were sacrificed on different days post-infection by cervical dislocation, lungs were removed aseptically and then homogenized in $1 \mathrm{ml}$ normal saline. Serial dilutions of the homogenized lung tissue were made, plated on nutrient agar plates, incubated at $37{ }^{\circ} \mathrm{C}$ for $24 \mathrm{~h}$ and quantitative bacterial counts were determined.

The lung homogenate from each mouse was also processed for the following parameters.

Malondialdehyde (MDA) estimation. The extent of tissue damage in terms of lipid peroxidation was estimated by measuring the amount of MDA by the method of Ohkawa et al. (1979). In brief, $0.2 \mathrm{ml}$ of the lung homogenate was mixed with $4 \mathrm{ml} 0.045 \mathrm{M}$ sulphuric acid, $1.5 \mathrm{ml}$ of freshly prepared $0.8 \%$ thiobarbituric acid and $0.2 \mathrm{ml} 8.1 \%$ SDS. This mixture was then kept in a boiling water bath for $1 \mathrm{~h}$. After cooling the mixture under tap water, $5.0 \mathrm{ml}$ butanol: pyridine $(15: 1)$ was added and the mixture was shaken vigorously. The contents were centrifuged at 4000 r.p.m. for $10 \mathrm{~min}$, the upper organic layer was taken in a separate tube and its $A_{532}$ was taken. The MDA concentration was expressed as $\mu \mathrm{mol}(\mathrm{mg} \text { protein })^{-1}$.

Myeloperoxidase (MPO) estimation. Pulmonary neutrophil infiltration was quantified by measuring the MPO activity using a spectrophotometric method as proposed by Greenberger et al. (1995). Briefly, the lungs were removed, weighed to determine the wet weight and then homogenized in $2 \mathrm{ml}$ homogenizing solution containing $50 \mathrm{mM}$ potassium phosphate buffer ( $\mathrm{pH}$ 6.0) with $0.5 \%$ hexadecyltrimethylammonium bromide and $5 \mathrm{mM}$ EDTA. The homogenate was sonicated and centrifuged at $15000 \mathrm{~g}$ for $15 \mathrm{~min}$. The supernatant was mixed in a ratio of $1: 15$ with assay buffer comprising $100 \mathrm{mM}$ potassium phosphate buffer (pH 6.0), $0.167 \mathrm{mg} \quad o$-dianisidine hydrochloride $\mathrm{ml}^{-1}$ and $0.0005 \%$ hydrogen peroxide. MPO activity was assayed by measuring the change in $A_{460}$ from $0 \mathrm{~min}$ to $4 \mathrm{~min}$ over intervals of $30 \mathrm{~s}$.

Nitric oxide (NO) estimation. The nitrite level was estimated in the lung homogenate according to the method of Tsai et al. (1997). Lung homogenate $(0.1 \mathrm{ml})$ was mixed with $0.4 \mathrm{ml} \mathrm{PBS}(0.1 \mathrm{M}, \mathrm{pH} 7.2)$ and $2 \mathrm{ml}$ Griess reagent. Then $2 \mathrm{ml}$ trichloroacetic acid was added and the mixture was vortexed and incubated for $20 \mathrm{~min}$. The mixture was then centrifuged at $14000 \mathrm{~g}$ for $10 \mathrm{~min}$ and the $A_{540}$ of the supernatant was taken. The nitrite concentration was determined from a standard curve prepared with $0.1 \mathrm{ml} 100 \mu \mathrm{M}$ sodium nitrite.

Estimation of TNF- $\alpha$ levels. Assay for TNF- $\alpha$ in the lung homogenates was performed by ELISA using a commercially available cytokine kit from BD Biosciences, i.e. BD OptEIA Mouse TNF- $\alpha$ ELISA. In brief, lungs were homogenized in $1 \mathrm{ml}$ lysis buffer containing $0.5 \%$ Triton X- 
$100,150 \mathrm{mM} \mathrm{NaCl}, 15 \mathrm{mM}$ Tris, $1 \mathrm{mM} \mathrm{CaCl}$ and $1 \mathrm{mM} \mathrm{MgCl}_{2}$ ( $\mathrm{pH}$ 7.4). Homogenates were then incubated on ice for $30 \mathrm{~min}$ and centrifuged at 2500 r.p.m. for $10 \mathrm{~min}$. Supernatants were then collected in sterile Eppendorf tubes, passed through a $0.45 \mu \mathrm{m}$ poresize filter and stored at $-70{ }^{\circ} \mathrm{C}$ for the assessment of TNF- $\alpha$ levels. The BD OptEIA test is a solid-phase sandwich ELISA. The wells were read at $450 \mathrm{~nm}$, the concentration of TNF- $\alpha$ in the test sample was determined from a standard curve prepared from the standard given along with the kit, and the results were expressed as $\mathrm{pg} \mathrm{ml}^{-1}$ of TNF- $\alpha$ released.

Histopathological examination. Lungs were removed aseptically, immersed in $10 \%$ formalin fixative and processed for histological examination. The lung tissue was embedded in paraffin wax and cut into 4-6 $\mu \mathrm{m}$ thick sections using a microtome. After this, the sections were stained with haematoxylin and eosin for assessment of the degree of neutrophil infiltration.

Statistical analysis. Results were analysed statistically by applying Student's $t$-test for comparing various parameters in treated and untreated control mice. Differences were considered statistically significant if $P$-values were less than 0.05 .

\section{RESULTS}

Effect of treatment with curcumin and augmentin individually or in combination on the bacterial count in the lungs of mice infected via the intranasal route with $K$. pneumoniae B5055

As shown in Fig. 1, an increase in the bacterial count was noticed in the lungs of control mice infected with $K$. pneumoniae from day 1 . It reached its peak on day 3 , after which the bacterial counts started declining. In the curcumin-treated group, no decrease in bacterial counts was observed and the counts were quite similar to those seen in the control group. In contrast, bacterial counts in the lungs of mice which received augmentin alone or in combination with curcumin showed a significant $(P$ $<0.05)$ decline. In this group also curcumin did not offer any extra protection in terms of bacterial numbers as the counts were similar in both groups.

\section{Effect of treatment with curcumin and augmentin individually or in combination on MPO levels in the lung homogenates of mice infected via the intranasal route with $K$. pneumoniae $B 5055$}

K. pneumoniae B5055-induced pulmonary infection in mice caused a profound increase in MPO activity (Fig. 2), indicating increased influx and activity of neutrophils at the site of infection in the lungs of the control group. Curcumin pre-treatment alone or in combination with augmentin significantly reduced $(P<0.05)$ the MPO activity in the lungs of infected mice by 2.5 -fold as compared to the control. In the group treated with augmentin alone, the MPO activity increased until the 3rd day and then declined. A comparison of MPO levels showed that they increased in all the groups until the 3rd post-infection day but the fall in MPO levels in curcumintreated animals was much higher than in the other groups on the 5th post-infection day $(P<0.05)$ onwards.

\section{Effect of treatment with curcumin and augmentin individually or in combination on the NO levels in the lung homogenates of mice infected via the intranasal route with $K$. pneumoniae $\mathrm{B} 5055$}

The results in Fig. 3 show that the lung homogenates of mice infected intranasally with $K$. pneumoniae B5055 contained detectable amounts of NO. There was an

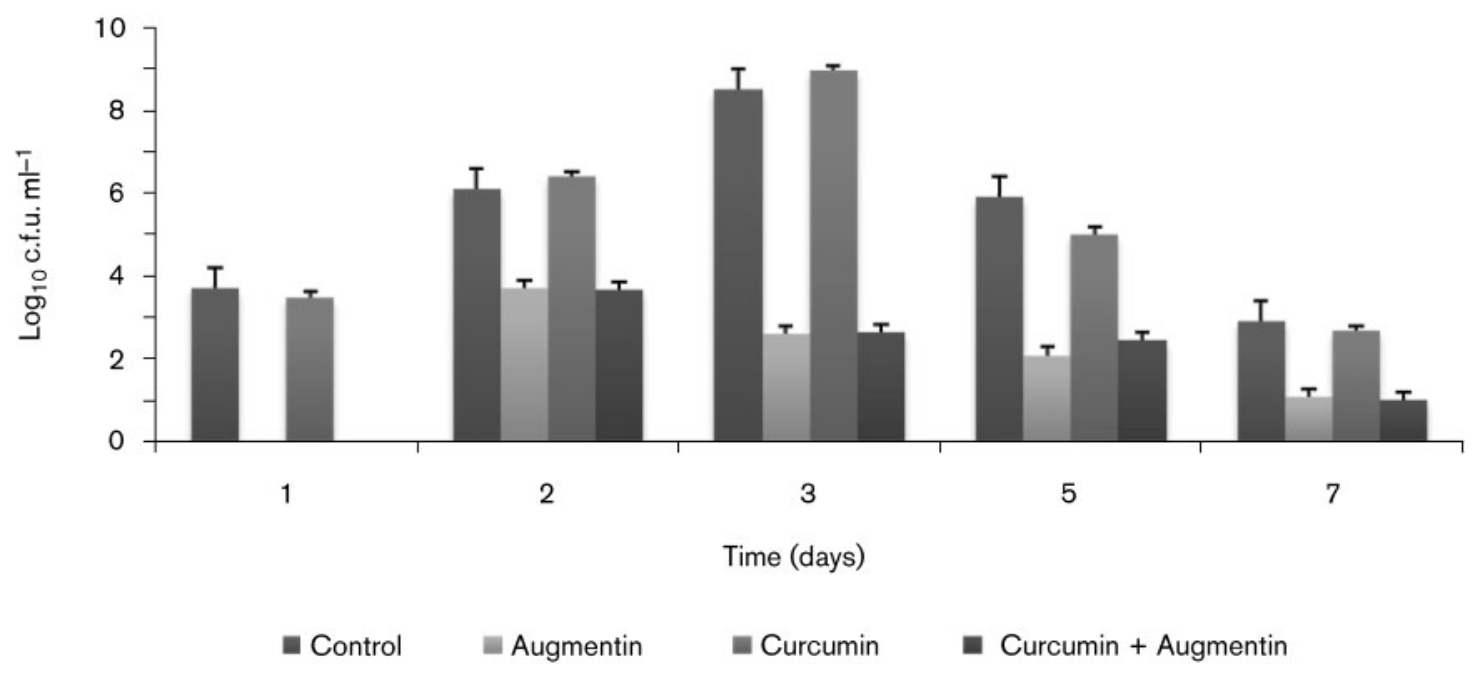

Fig. 1. Effect of treatment with curcumin and augmentin individually or in combination on the bacterial count ( $\log _{10}$ c.f.u. $\mathrm{ml}^{-1}$ ) in the lungs of mice infected via the intranasal route with K. pneumoniae B5055. No sample was taken and processed on day 1 in the augmentin- and augmentin + curcumin-treated groups. 


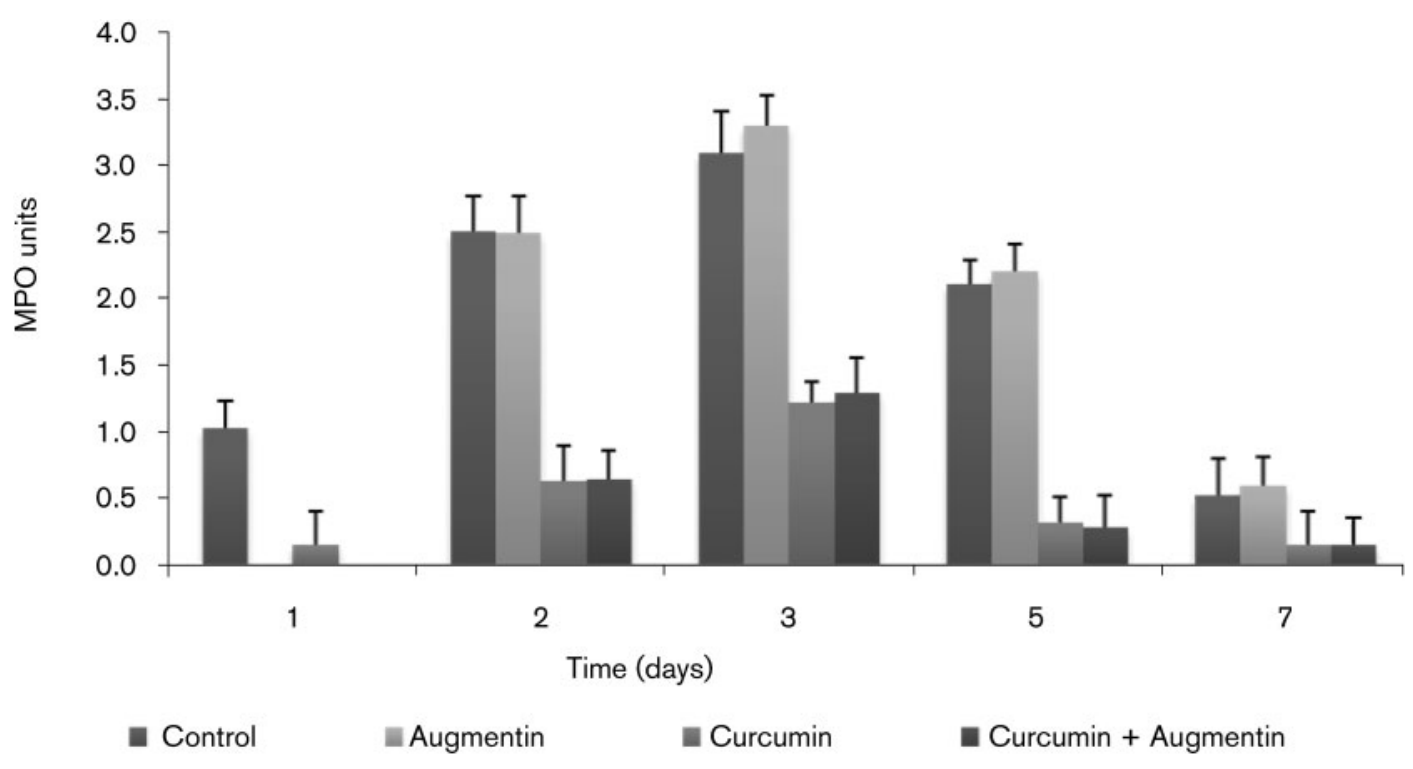

Fig. 2. Effect of treatment with curcumin and augmentin individually or in combination on MPO levels (MPO units) in lung homogenates of mice infected via the intranasal route with $K$. pneumoniae B5055. No sample was taken and processed on day 1 in the augmentin- and curcumin + augmentin-treated groups.

increase in NO production in the control animals and maximum levels were observed on the 3rd day postinfection. Levels of NO in curcumin-treated groups were lower and there was no significant difference in levels of $\mathrm{NO}$ in the curcumin- and curcumin + augmentin-treated groups. Treatment with augmentin alone did not cause a decrease in the NO concentration and the levels were similar to those seen in the control group.

\section{Effect of treatment with curcumin and augmentin individually or in combination on the MDA levels in the lung homogenates of mice infected via the intranasal route with $K$. pneumoniae B5055}

Fig. 4 depicts the level of MDA in the lungs of mice infected with K. pneumoniae B5055. MDA levels increased significantly in the lungs of animals infected with $K$.

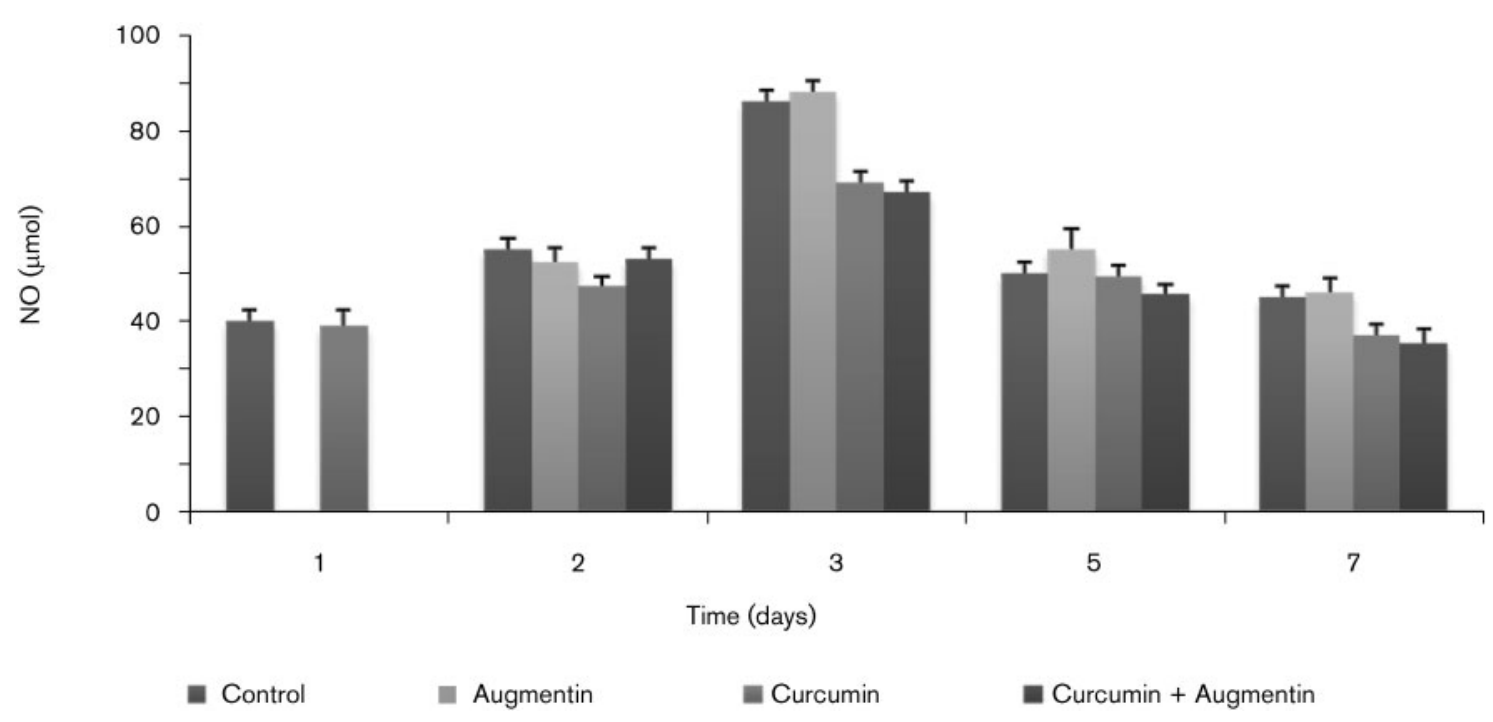

Fig. 3. Effect of treatment with curcumin and augmentin individually or in combination on the NO levels ( $\mu$ mol) in lung homogenates of mice infected via the intranasal route with $K$. pneumoniae B5055. No sample was taken and processed on day 1 in the augmentin- and curcumin + augmentin-treated groups. 


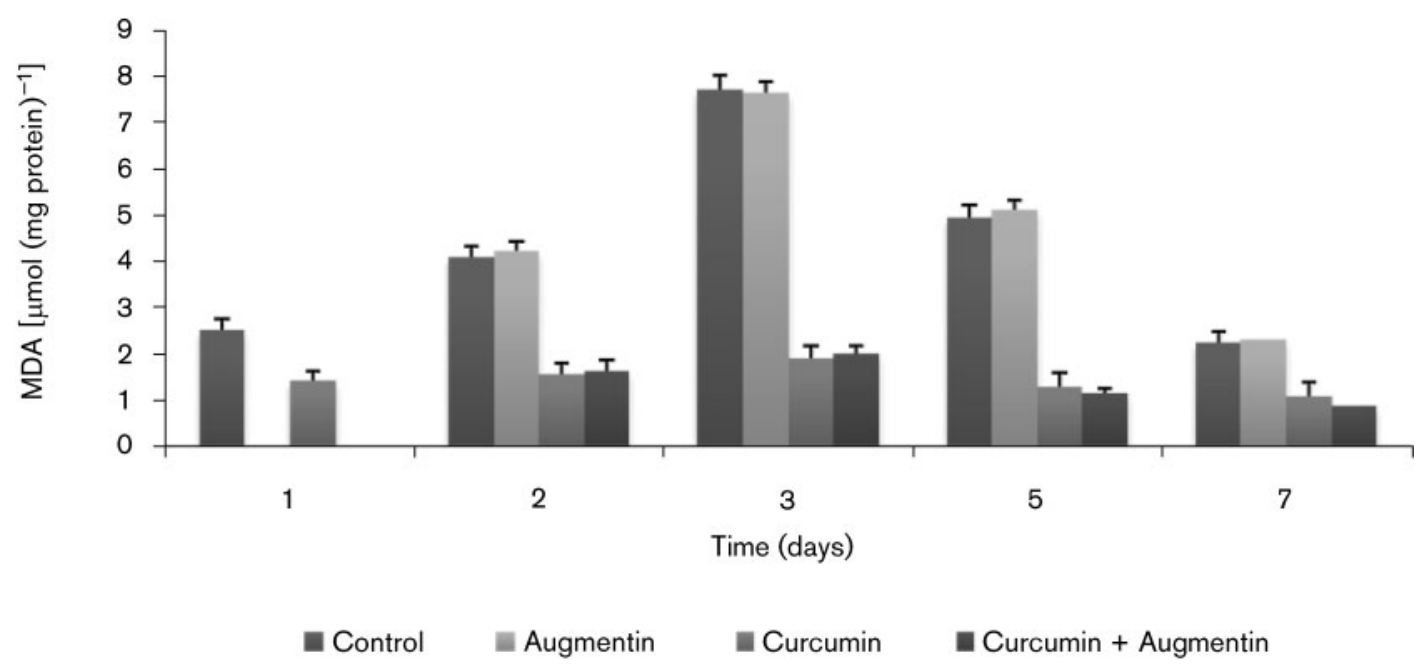

Fig. 4. Effect of treatment with curcumin and augmentin individually or in combination on the MDA levels [ $\mu \mathrm{mol}\left(\mathrm{mg}\right.$ protein) $\left.{ }^{-1}\right]$ in the lung homogenates of mice infected via the intranasal route with $K$. pneumoniae B5055. No sample was taken and processed on day 1 in the augmentin- and augmentin + curcumin-treated groups.

pneumoniae B5055, reached a peak on the 3rd day and thereafter started declining. MDA levels in the augmentintreated group were quite similar to the levels in the control group. Animals which were treated with curcumin alone or in combination with augmentin showed a fourfold decrease, thereby indicating reduced injury to lung tissue. A comparison of MDA levels on different days showed curcumin to be effective from day 1 following infection.

\section{Effect of treatment with curcumin and augmentin individually or in combination on the TNF- $\alpha$ levels in the lungs of mice infected via the intranasal route with $K$. pneumoniae $B 5055$}

Pro-inflammatory cytokines such as TNF- $\alpha$ play an important role during the pathogenesis of $K$. pneumoniae B5055-induced pneumonia. As shown in Fig. 5, the levels of TNF- $\alpha$ increased significantly following bacterial infection and maximum levels were observed in the control groups on the 3rd post-infection day. Treatment with curcumin alone as well as in combination with augmentin downregulated TNF- $\alpha$ production in comparison to the control group. However, augmentin treatment alone did not show any negative effect on TNF- $\alpha$ production as the levels observed were quite similar to those seen in the control group on all days following infection.

\section{Effect of treatment with curcumin and augmentin individually or in combination on neutrophil infiltration into the lungs of mice infected via the intranasal route with $K$. pneumoniae B5055}

Curcumin treatment alone or in combination with augmentin significantly decreased the neutrophil infiltration in the lungs of mice infected with $K$. pneumoniae
B5055 (Fig. 6c, d) as compared to the control group (Fig. 6a). However, augmentin treatment alone did not show any effect on neutrophil infiltration in the lungs of infected animals (Fig. 6b).

\section{DISCUSSION}

An attempt was made in this study to explore the antiinflammatory effect of curcumin alone as well as in combination with augmentin in an acute lung injury model. On the basis of the results of all the different parameters employed in this study, induction of acute lung inflammation following instillation of $K$. pneumoniae was observed. Pre-treatment of animals with curcumin 15 days prior to infection with $K$. pneumoniae did not give rise to any antibacterial activity. In contrast, bacterial counts in animals treated with augmentin alone or in combination with curcumin declined following treatment, indicating that curcumin did not interfere with the antibacterial effect of augmentin. The results are in agreement with an earlier finding from our laboratory where it was shown that immunomodulatory agents do not interfere with antibiotic action (Kumar \& Chhibber, 2008) and hence can be used in conjunction.

Acute inflammation in the lungs is characterized by increased activity of neutrophils (Kooguchi et al., 1998; Maus et al., 2003). The migration of neutrophils at the site of acute inflammation involves the activity of various inflammatory cytokines and chemokines, and expression of various cell surface leukocyte and endothelial adhesion molecules (Rosseau et al., 2000; Robson et al., 2001; Maus et al., 2002). There are reports showing that infection of airway epithelial cells by pathogens such as Streptococcus pneumoniae, Mycoplasma pneumoniae and group B 


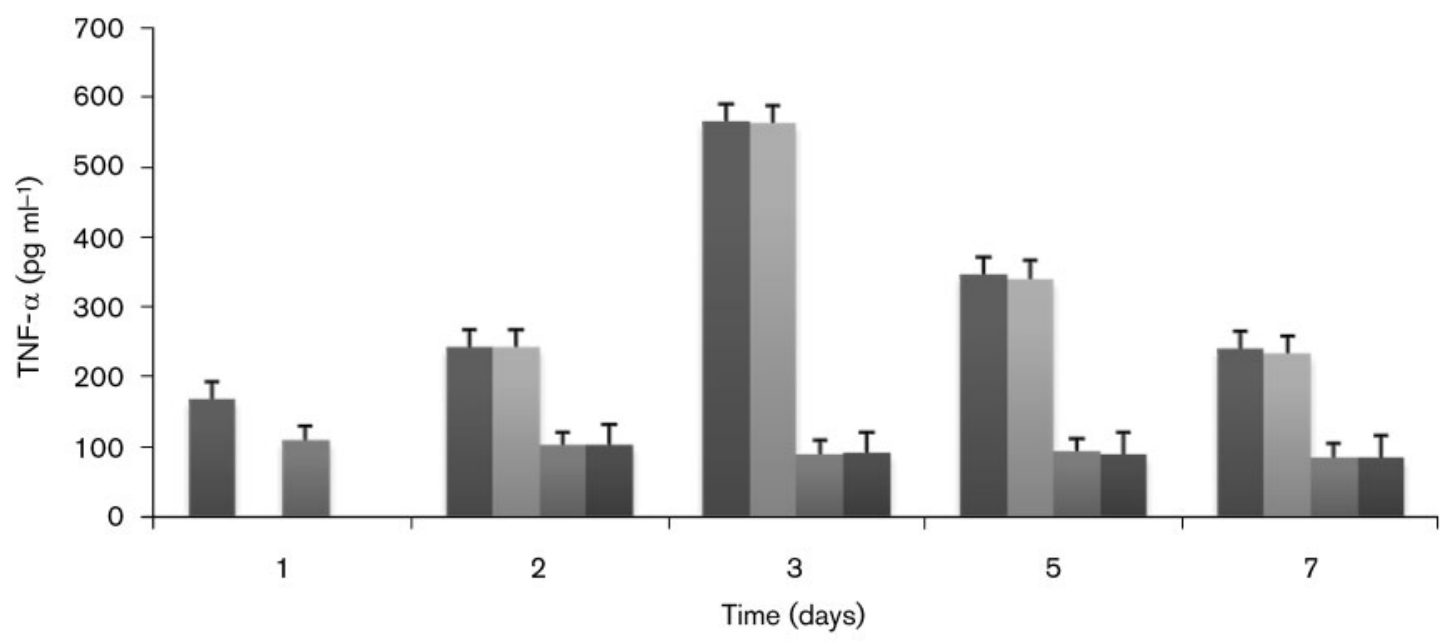

- Control augmentin $\quad$ Curcumin Curcumin + Augmentin

Fig. 5. Effect of treatment with curcumin and augmentin individually or in combination on the TNF- $\alpha$ levels (pg ml ${ }^{-1}$ ) in the lungs of mice infected via the intranasal route with K. pneumoniae B5055. No sample was taken and processed on day 1 in the augmentin- and curcumin + augmentin-treated groups.

streptococci triggers the secretion of interleukin-8 and increases the surface levels of intercellular cell adhesion molecule-1 (ICAM-1) (Doran et al., 2002; Murdoch et al., 2002; Yang et al., 2002; Mikamo et al., 2004). It is likely that infection with $\mathrm{K}$. pneumoniae B5055 also resulted in an increase in ICAM-1 levels, which might have contributed towards the influx of neutrophils in the lung alveoli as confirmed by histopathological examination of tissue. There have been reports in the past that curcumin downregulates neutrophil infiltration in the tissue spaces by decreasing the expression of adhesion molecules such as ICAM-1 and vascular cell adhesion molecule- 1 on endothelial cells (Ohene-Abuakwa \& Pignatelli, 2000). Similar results were observed in this study on histopathological examination of lung tissue of mice fed on curcumin. The animals which were treated with curcumin alone or in combination with augmentin showed no signs of inflammation and the lung alveoli were completely devoid of neutrophils. However, treatment with augmentin alone had no effect on neutrophil infiltration in the lung alveoli and the alveoli were completely filled with neutrophils similar to that seen in the lungs of the control group. Enzyme MPO is also an indirect indicator of neutophil infiltration and its levels correlated with neutrophil numbers on all days of infection.

NO generated during acute infection causes tissue damage by acting as a free radical and by generating more active species such as peroxynitrite which lead to lipid peroxidation of the cell membrane of various host cells (Kooy et al., 1995; Sittipunt et al., 2001) and result in acute lung injury (Wang et al., 2002; Baron et al., 2004). NO synthase inhibitors are known to decrease acute lung injury and microvascular leakage caused during endotoxaemia (Kristof et al., 1998).
However, NO synthase inhibition with inhibitors such as NGmonomethyl-L-arginine in patients with acute lung injury worsened their cardiac function and increased the mortality rate (Nava et al., 1991; Cobb et al., 1992; Minnard et al., 1994). In contrast, curcumin alone or in combination with augmentin in the present study led to decreased NO free radical production in the lungs of mice infected with $K$. pneumoniae B5055 without any adverse effects. This can be explained on the basis of earlier findings as curcumin has been found to neutralize both reactive oxygen and reactive nitrogen species, which play an important role during inflammatory processes such as inflammatory bowel disease (Brouet \& Ohshima, 1995; Bhaumik et al., 2000; Ukil et al., 2003). Since augmentin alone showed no effect on NO generation, it is concluded that in combination with curcumin both antibacterial and anti-inflammatory effects can be generated using both the agents.

The level of cellular injury which might have occurred due to release of reactive oxygen species as a result of lipid peroxidation was estimated in terms of MDA levels in lung homogenates of mice suffering from acute pneumonia. In an earlier study, Kaur et al. (2006) demonstrated that curcumin reduced the levels of MDA in a model of endotoxin-induced hepatic dysfunction. Treatment of mice with curcumin alone or in combination with augmentin in the present study also resulted in decreased MDA levels in infected lung tissue thereby reducing lung injury. These results further suggest that curcumin can be used as an adjunct therapy along with the antibiotic augmentin, resulting in clearance of bacteria from the lungs along with protection to tissue from injury due to an exaggerated immune response during pneumonia. Treatment with curcumin alone or in combination 
(a)

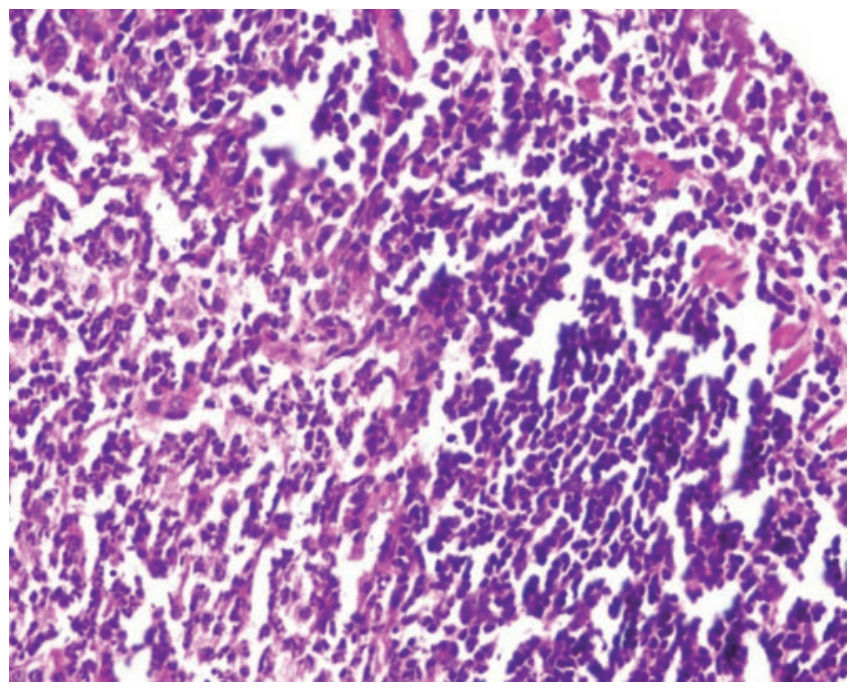

(c)

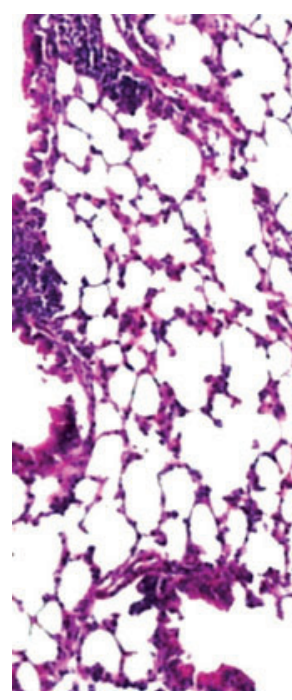

(b)

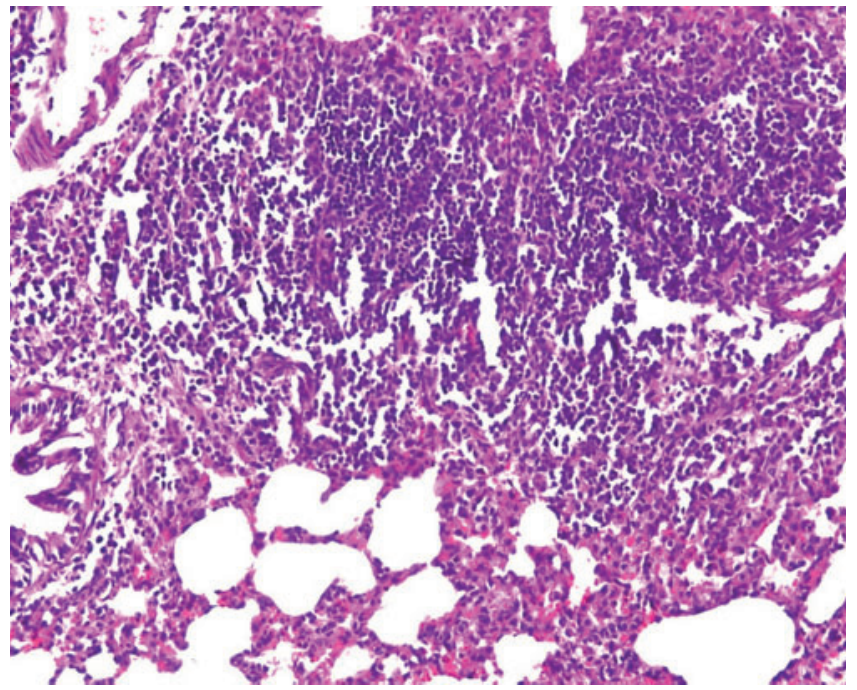

(d)

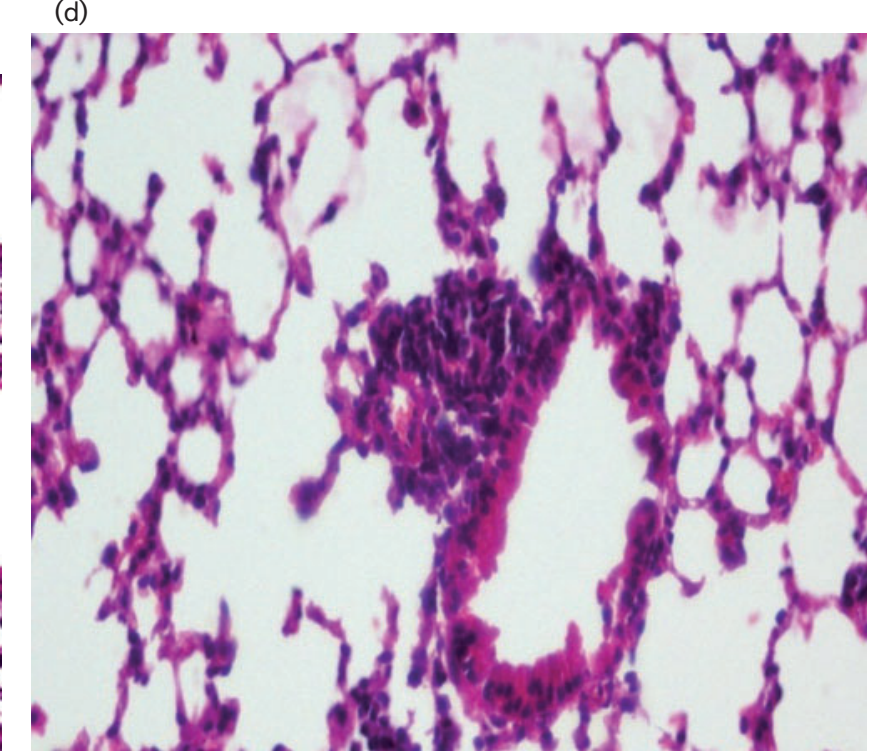

Fig. 6. (a) Lungs of mice suffering from K. pneumoniae B5055-induced pneumonia and treated with normal saline alone, i.e. the control group. (b) Lungs of mice suffering from K. pneumoniae B5055-induced pneumonia and treated with augmentin alone. (c) Lungs of mice which were fed orally with curcumin for 15 days then infected with K. pneumoniae. (d) Lungs of mice which were treated with both curcumin and augmentin.

with augmentin also resulted in decreased production of lung TNF- $\alpha$. These results are in accordance with earlier observations where curcumin was shown to downregulate levels of TNF- $\alpha$ during inflammatory bowel disease and chronic lung disease (Literat et al., 2001; Ukil et al., 2003). These results are significant as TNF- $\alpha$ is known to play an important role in the pathogenesis of acute lung infection (Shalaby et al., 1985; Marcho et al., 1991; Tsan et al., 1995).

The results of the present study clearly demonstrate the positive effect of curcumin as reduced acute lung injury associated with pneumonia was observed in treated animals. The major protection was due to its immunomodulatory or anti-inflammatory action, which resulted in decreased production of various inflammatory markers such as TNF- $\alpha$, NO, MPO and MDA and neutrophil recruitment. As the immune system plays an important role in the pathogenesis of pneumonia-associated lung injury and mortality, this strategy will prove meaningful in preventing increased inflammatory pulmonary damage associated with pneumonia following bacterial infection. Moreover, since curcumin has no side effects, is costeffective and is a part of our daily diet, it can serve as a very good alternative or complementary form of medicine to curb inflammation. 


\section{REFERENCES}

Aggarwal, B. B. \& Sung, B. (2008). Pharmacological basis for the role of curcumin in chronic diseases: an age-old spice with modern targets. Trends Pharmacol Sci 30, 85-94.

Ammon, H. P. T. \& Wahl, M. A. (1991). Pharmacology of Curcuma longa. Planta Med 57, 1-7.

Baron, R. M., Carvajal, I. M., Liu, X., Okabe, R. O., Fredenburgh, L. E., Macias, A. A., Chen, Y. H., Ejima, K., Layne, M. D. \& Perrella, M. A. (2004). Reduction of nitric oxide synthase 2 expression by distamycin A improves survival from endotoxemia. J Immunol 173, 41474153.

Bhaumik, S., Jyothi, M. D. \& Khar, A. (2000). Differential modulation of nitric oxide production by curcumin in host macrophages and NK cells. FEBS Lett 483, 78-82.

Brouet, I. \& Ohshima, H. (1995). Curcumin, an anti-tumor promoter and anti-inflammatory agent, inhibits induction of nitric oxide synthase in activated macrophages. Biochem Biophys Res Commun 206, 533-540.

Cheng, A. L., Hsu, C. H., Lin, J. K., Hsu, M. M., Ho, Y. F., Shen, T. S., Ko, J. Y., Lin, J. T., Lin, B. R. \& other authors (2001). Phase I clinical trial of curcumin, a chemopreventive agent, in patients with high-risk or pre-malignant lesions. Anticancer Res 21, 2895-2900.

Cobb, J. P., Natanson, C., Hoffman, W. D., Lodato, R. F., Banks, S., Koev, C. A., Solomon, M. A., Elin, R. J., Hosseini, J. M. \& Danner, R. L. (1992). $\mathrm{N}$-amino-L-arginine, an inhibitor of nitric oxide synthase, raises vascular resistance but increases mortality rates in awake canines challenged with endotoxin. J Exp Med 176, 1175-1182.

Cortes, G., Borrell, N., de Astroza, B., Gomez, C., Sauleda, J. \& Alberti, S. (2002). Molecular analysis of the contribution of the capsular polysaccharide and the lipopolysaccharide side chain to the virulence of Klebsiella pneumoniae in a murine model of pneumonia. Infect Immun 70, 2583-2590.

Doran, K. S., Chang, J. C., Benoit, V. M., Eckmann, L. \& Nizet, V. (2002). Group B streptococcal beta-hemolysin/cytolysin promotes invasion of human lung epithelial cells and the release of interleukin8. J Infect Dis 185, 196-203.

Greenberger, M. J., Strieter, R. M., Kunkel, S. L., Danforth, J. M., Goodman, R. E. \& Standiford, T. J. (1995). Neutralization of IL-10 increases survival in a murine model of Klebsiella pneumoniae. J Immunol 155, 722-729.

Held, T. K., Mielke, M. E. A., Chedid, M., Unger, M., Trautman, M., Huhn, D. \& Cross, A. S. (1998). Granulocyte colony-stimulating factor worsens the outcome of the experimental Klebsiella pneumoniae pneumonia through direct interaction with the bacteria. Blood 91, 2525-2533.

Huang, M. T., Lou, Y. R., Ma, W., Newmark, H. L. \& Reuhl, K. R. (1994). Inhibitory effects of dietary curcumin on forestomach, duodenal and colon carcinogenesis in mice. Cancer Res 54, 5841-5847.

Huang, M. T., Newmark, H. L. \& Frenkel, K. (1997). Inhibitory effects of curcumin on tumorigenesis in mice. J Cell Biochem Suppl 27, 26-34.

Hunter, P. A., Coleman, H. K., Fisher, J. \& Taylor, D. (1980). In vitro synergistic properties of clavulanate with amoxicillin. J Antimicrob Chemother 6, 455-470.

Kaur, G., Tirkey, N., Bharrhan, S., Chanana, V., Rishi, P. \& Chopra, K. (2006). Inhibition of oxidative stress and cytokine activity by curcumin in amelioration of endotoxin-induced experimental hepatoxicity in rodents. Clin Exp Immunol 145, 313-321.

Kawamori, T., Lubet, R., Steele, V. E., Kelloff, G. J., Kaskey, R. B. \& Rao, C. V. (1999). Chemopreventive effect of curcumin, a naturally occurring anti-inflammatory agent, during the promotion/progression stages of colon cancer. Cancer Res 59, 597-601.
Kooguchi, K., Hashimoto, S., Kobayashi, A., Kitamura, Y., Kudoh, I., Wiener-Kronish, J. \& Sawa, T. (1998). Role of alveolar macrophages in initiation and regulation of inflammation in Pseudomonas aeruginosa pneumonia. Infect Immun 66, 3164-3169.

Kooy, N. W., Royall, J. A., Ye, Y. Z., Kelly, D. R. \& Beckman, J. S. (1995). Evidence for in vivo peroxynitrite production in human acute lung injury. Am J Respir Crit Care Med 151, 1250-1254.

Kristof, A. S., Goldberg, P., Laubach, V. \& Hussaiu, S. N. (1998). Role of inducible nitric oxide synthase in endotoxin-induced acute lung injury. Am J Respir Crit Care Med 158, 1883-1889.

Kumar, V. \& Chhibber, S. (2008). Anti-inflammatory effect of thalidomide alone or in combination with augmentin in Klebsiella pneumoniae B5055 induced acute lung infection in BALB/c mice. Eur J Pharmacol 592, 146-150.

Legnani, D. (1997). Role of oral antibiotics in treatment of community-acquired lower respiratory tract infections. Diagn Microbiol Infect Dis 27, 41-47.

Literat, A., Su, F., Norwicki, M., Durand, M., Ramanathan, R., Jones, C. A., Minoo, P. \& Kwong, K. Y. (2001). Regulation of proinflammatory cytokine expression by curcumin in hyaline membrane disease (HMD). Life Sci 70, 253-256.

Marcho, Z., White, J. E., Higgins, P. J. \& Tsan, M. F. (1991). Tumor necrosis factor enhances endothelial cell susceptibility to oxygen toxicity: role of glutathione. Am J Respir Cell Mol Biol 5, 556-562.

Maus, U., Huwe, J., Ermert, L., Ermert, M., Seeger, W. \& Lohmeyer, J. (2002). Molecular pathways of monocyte emigration into the alveolar air space of intact mice. Am J Respir Crit Care Med 165, 9598.

Maus, U. A., Waelsch, K., Kuzeil, W. A., Delbeck, T., Mack, M. \& Blackwell, T. S. (2003). Monocytes are potent facilitators of alveolar neutrophil emigration during lung inflammation: role of CCL2CCR2 axis. J Immunol 170, 3273-3278.

Mikamo, H., Johri, A. K., Paoletti, L. C., Madoff, L. C. \& Onderdonk, A. B. (2004). Adherence to, invasion by, and cytokine production in response to serotype VIII group B streptococci. Infect Immun 72, 4716-4722.

Minnard, E. A., Shou, J., Naama, H., Cech, A., Gallagher, H. \& Daly, J. M. (1994). Inhibition of nitric oxide synthesis is detrimental during endotoxemia. Arch Surg 129, 142-148.

Murdoch, C., Read, R. C., Zhang, Q. \& Finn, A. (2002). Choline binding protein A of Streptococcus pneumoniae elicits chemokine production and expression of intercellular adhesion molecule 1 (CD54) by human alveolar epithelial cells. J Infect Dis 186, 1253-1260.

Nava, E., Palmer, R. M. \& Moncada, S. (1991). Inhibition of nitric oxide synthesis in septic shock: how much is beneficial? Lancet 338, 1555-1557.

Ohene-Abuakwa, Y. \& Pignatelli, M. (2000). Adhesion molecules in cancer biology. Adv Exp Med Biol 465, 115-126.

Ohkawa, H., Ohishi, N. \& Yagi, K. (1979). Assay of lipid peroxides in animal tissues by thiobarbituric acid reaction. Anal Biochem 95, 351358.

Robson, R. L., McLoughlin, R. M., Witowski, J., Loetschler, P., Wilkinson, T. S., Jones, S. A. \& Topley, N. (2001). Differential regulation of chemokine production in human peritoneal mesothelial cells: IFN- $\gamma$ controls neutrophil migration across the mesothelium in vitro and in vivo. J Immunol 167, 1028-1031.

Rosseau, S., Hammerl, P., Maus, U., Walmrath, H. D., Schutte, H., Grimminger, F., Seeger, W. \& Lohmeyer, J. (2000). Phenotypic characterization of alveolar monocyte recruitment in acute respiratory distress syndrome. Am J Physiol Lung Cell Mol Physiol 279, L25L30. 
Saint, S. \& Chenoweth, C. E. (2003). Biofilms and catheter-associated urinary tract infections. Infect Dis Clin North Am 17, 411-432.

Shalaby, M. R., Aggarwal, B. B., Rindeknecht, E., Svedersky, L. P., Finkle, B. S. \& Palladino, M. A. (1985). Activation of human polymorphonuclear neutrophil functions by interferon-gamma and tumor necrosis factors. J Immunol 135, 2069-2073.

Sharma, R. A., Gescher, A. J. \& Steward, W. P. (2005). Curcumin: the story so far. Eur J Cancer 41, 1955-1968.

Sittipunt, C., Steinberg, K. P., Ruzinski, J. T., Myles, C., Zhu, S., Goodman, R. B., Hudson, L. D., Matalon, S. \& Martin, T. R. (2001). Nitric oxide and nitrotyrosine in the lungs of patients with acute respiratory distress syndrome. Am J Respir Crit Care Med 163, 503510 .

Strimpakos, A. S. \& Sharma, R. A. (2008). Curcumin: preventive and therapeutic properties in laboratory studies and clinical trials. Antioxid Redox Signal 10, 511-545.

Struve, C. \& Krogfelt, K. A. (2004). Pathogenic potential of environmental Klebsiella pneumoniae isolates. Environ Microbiol 6, 584-590.

Tasaka, S., Hasegawa, N. \& Ishizaka, A. (2002). Pharmacology of acute lung injury. Pulm Pharmacol Ther 15, 83-95.

Tsai, W. C., Strieter, R. M., Zisman, D. A., Wilkowski, J. M., Bucknell, K. A., Chen, G. \& Standiford, T. J. (1997). Nitric oxide is required for effective innate immunity against Klebsiella pneumoniae. Infect Immun 65, 1870-1875.

Tsan, M. F., White, J. E., Michelsen, P. B. \& Wong, G. H. (1995). Pulmonary $\mathrm{O}_{2}$ toxicity: role of endogenous tumor necrosis factor. Exp Lung Res 21, 589-597.

Ukil, A., Maity, S., Karmakar, S., Datta, N., Vedasiromoni, J. R. \& Das, P. K. (2003). Curcumin, the major component of food flavour turmeric, reduces mucosal injury in trinitrobenzene sulphonic acidinduced colitis. Br J Pharmacol 139, 209-218.

Wang, L. F., Patel, M., Razavi, H. M., Weicker, S., Joseph, M. G., McCormack, D. G. \& Mehta, S. (2002). Role of inducible nitric oxide synthase in pulmonary microvascular protein leak in murine sepsis. Am J Respir Crit Care Med 165, 1634-1639.

Woo, P. C. Y., Pau, S. K. P. \& Yuen, K.-Y. (2002). Macrolides as immunomodulatory agents. Curr Med Chem Anti Inflamm Anti Allergy Agents 1, 131-141.

Yadav, V., Sharma, S., Harjai, K., Mohan, H. \& Chhibber, S. (2003). Induction and resolution of lobar pneumonia following intranasal instillation with Klebsiella pneumoniae in mice. Indian J Med Res 118 , $47-52$.

Yang, J., Hooper, W. C., Phillips, D. J. \& Talkington, D. F. (2002). Regulation of proinflammatory cytokines in human lung epithelial cells infected with Mycoplasma pneumoniae. Infect Immun 70, 36493655. 